\title{
Archaeology, Stone Tools and RIMAPS Technique: A Quantitive Characterization of Use-Wear Traces.
}

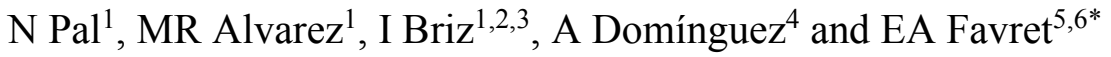 \\ ${ }^{1}$ CADIC-CONICET, Ushuaia, Argentina. \\ ${ }^{2}$ Harvard University, D. Rockefeller Center for Latin American Studies (Visiting Scholar), \\ Cambridge, USA. \\ ${ }^{3}$ Dept. of Archaeology, University of York, (Associate Researcher), York, UK. \\ ${ }^{4}$ CAC, CNEA, San Martín, Argentina. \\ ${ }^{5}$ CNIA, INTA, Hurlingham, Argentina. \\ ${ }^{6}$ CONICET, Buenos Aires, Argentina. \\ *Corresponding author: favret.eduardo@inta.gob.ar
}

Archaeology relies on material remains to attain a broad comprehensive understanding of human evolution, creating undeniable challenges to the methodological field.

Microscopy and image techniques have had a paramount role in this field of research since they provide different analytical lines to solve problems related to human tools. One of these problems entails to identify how a lithic tool was used. It is known, following the Russian researcher Sergei Semenov, that different working processes leave singular traces on the surface of a stone tool in contact with the working material [1].

The search of quantitative variables that allow characterizing these traces has been an important aim since the beginning of the use-wear method with different degrees of success [2]. Despite of the limitations of the methods applied, most of them showed differences on lithic tools roughness and texture according to the worked material. Following this line of research, we applied Rotated Image with Maximum Average Power Spectrum (RIMAPS) technique in order to detect patterns that characterize the structural modifications that occur on stone tool as a result of its use [3]. RIMAPS is a novel characterization technique that allows revealing the orientation and characteristics of the topographic pattern of a surface.

In the present paper, quantitative patterns on chert and quarzite tools that worked hide, wood and bone were distinguished and the incidence of the mineralogical and textural properties of the rocks in the formation processes of use-wear traces was analyzed. RIMAPS technique was performed on digitized images, similar magnification and more than 30 images per tool, taken with a scanning electronic microscope (FEI Quanta 200). Figure 1 shows the RIMAPS spectra of an unused chert tool and one that worked hide. The peaks appearing in the resulting plots indicate the surface pattern orientation and its characteristic topographic form.

This study reveals, in quantitatively terms, the micro-topographic transformation produced on a lithic surface as a consequence of its usage. It has allowed the observation of the development of the usewear traces that happens during the work process. Although these traces show the general features of wear related to work in mineral substances, they show some specific characteristics that are related to the used materials, the tools employed and the activities carried out. RIMAPS could become a powerful and supportive tool that can be successfully applied in use-wear research. 
References

[1] S.A. Semenov in "Prehistoric Technology". Moonraker Press, Wiltshire. (1964), p. 1.

[2] W.J. Stemp, A.S. Watson, A. Evans, Surf. Topogr.: Metrol. Prop. 4 (2016), p. 13001.

[3] N. Fuentes, E.A. Favret, J. Microsc. 206 (2002), p. 72.

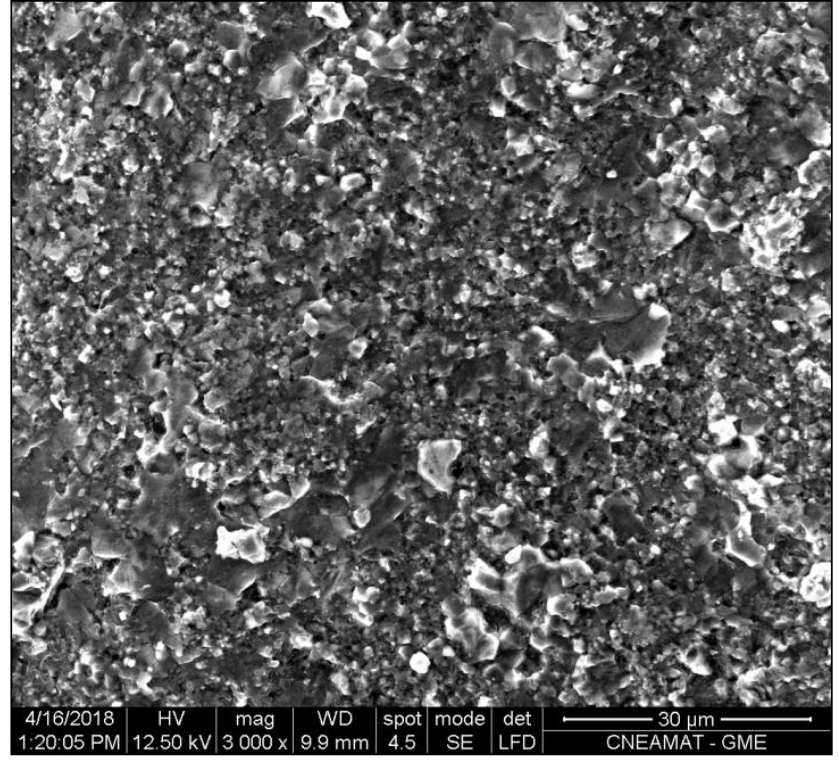

A

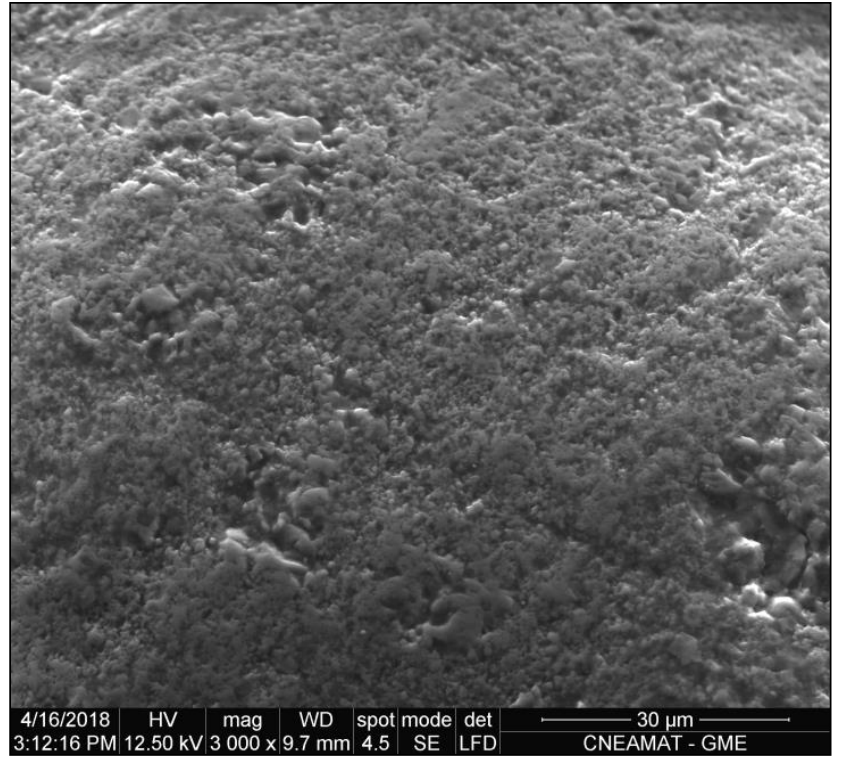

B

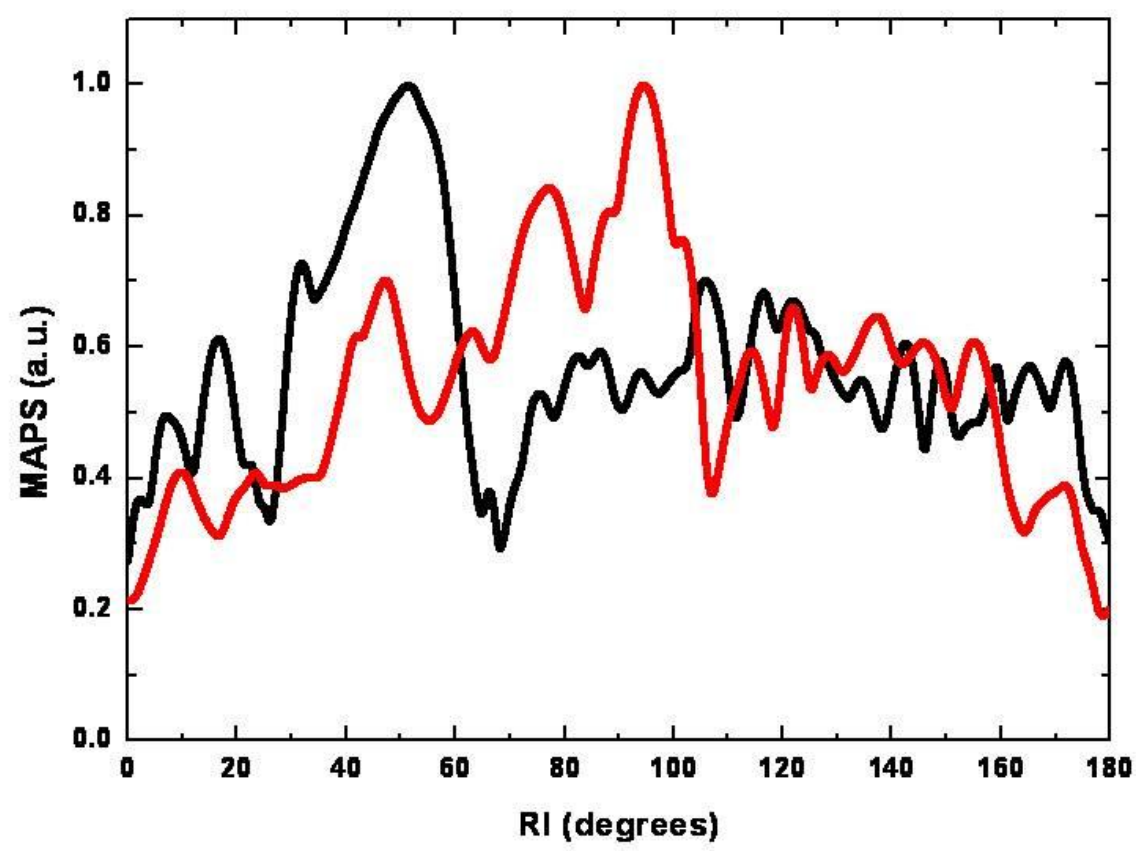

C

Figure 1. A) SEM micrograph of an unused chert tool. B) SEM micrograph of a chert tool that worked hide. C) RIMAPS spectra of images A (black curve) and B (red curve). 